\title{
Structural Analysis of Wind Sail
}

\author{
Jeeva Joy \\ ${ }^{I}$ (Department of Civil Engineering, KMEA Engineering College, Ernakulam, India)
}

\begin{abstract}
To bring down the operating costs in maritime traffic expenditure, the usage of fuel has to be reduced. For this the only possible solution is that to find alternative energy sources. In open sea easily available energy sources are solar energy and wind energy. Among them Wind energy is best suited for serving the purpose due to its availability and ease of transformation. In the present study the effect of wind sail on ship is analysed. Wind sail was modelled numerically using CFD technique. The influence of the main sail design variables such as draft, camber and angle of attack due to the forces coefficients of sail. One sail model was developed, and sail model was simulated at an $90^{\circ}$ angle of attack for maximum thrust .And conduct structural analysis for the sail model.
\end{abstract}

Keywords :CFD, FEM, Mast, Sail, Wind energy

\section{INTRODUCTION}

Oil is a major energy source powering the global economy and supplying $95 \%$ of the total energy fuelling world transport. Like other modes, maritime transport relies heavily on oil for propulsion and, in view of limitations imposed by existing technology and cost is not yet in opposition to adopt effective energy substitutes (ex- bio fuels, solar \& wind). At the same time fossil fuels reserves are finite. oil extraction is becoming costly and oil production overall is believed to either already have peaked or to reach its maximum level soon. The dependency of maritime transport sector on a source of energy that is becoming increasingly scarce and more costly to produce, for using alternate energy may entail some serious implications for the cost of maritime transport services. With over of the volume of global merchandise trade being carried by sea, the question of how changes in oil prices affect ocean shipping rates is of considerable relevance.

Investigating the possibility of using alternate fuel resources for maritime traffic it's been found that commercial wind driven ship have practically vanished from the sea during the twentieth century. Wind as a means of commercial propulsion did make a brief and limited come back during the 1980's.

Indeed a lot of research has taken place regarding the prediction of performance and propulsive ability of sailing crafts. However controllability of sailing crafts doesn't seem to have received much attention in spite of many uncertainties and risks involved in harnessing wind power especially with regard to the ability to manoeuvre, ability to enter and leave port in high density traffic, response to wind gusts etc. There is a need to predict the course-keeping and manoeuvring characterises of sailing crafts right from the design stage in order to reduce the risk of collision, grounding etc. Also, in the wake of the recent causalities involving sailing crafts, vessels response to wind gusts is another area of concern which needs to be studied

So now we are facing a big opportunity to explore renewable energy. Wind is the best solutions for shipping. It's clearly evident that in order to bring down the operating costs in maritime traffic expenditure on fuel has to be reduced. For this the only possible solution is that to find alternative energy sources. In open sea easily available energy sources are solar energy and wind energy. Among them Wind energy is best suited for serving the purpose due to its availability and ease of transformation to other source. Since it is sustainable, easily accessible, cost and emission-free.

\section{ANAlysis Of SAIL Of ShIP USING CFD}

Shape of sail is an airfoil or aerofoil. Standard airfoil is NACA0018 is used in the analysis. Analysis is done using Computational Fluid Dynamics (CFD) software. A standard airfoil section is chosen for analysis. The airfoil section is NACA 0018.

Table 1:Specification of NACA 0018

\begin{tabular}{|l|l|}
\hline Specification & Values \\
\hline Camber & $0 \%$ \\
\hline Draft & $0 \%$ \\
\hline Thickness & $18 \%$ \\
\hline
\end{tabular}




\subsection{Pre-processing}

Pre-processing includes creation of geometry, adding domain around the geometry and descretization of the domain.

\subsubsection{Creation of Geometry}

The coordinates of the sail is taken from NACA airfoil public domain and the coordinates are imported into ICEM CFD 13 and will get the wire frame model of sail form. CFD is the interaction between the flow and surface. So wire frame is converted into surface model.

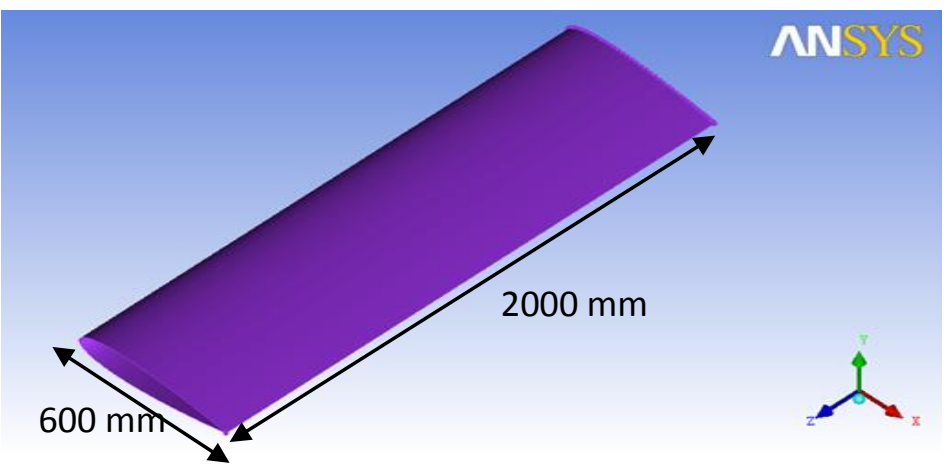

Fig 1: Geometry of NACA 0018

\subsubsection{Creation of domain}

The extent of domain for computation was chosen as per ITTC 1999 recommendations. Accordingly the domain extents are:

$$
\begin{gathered}
\mathrm{L} \leq \mathrm{X} \leq \mathrm{L} \\
-\mathrm{L} / 2 \leq \mathrm{Y} \leq \mathrm{L} / 2 \\
-\mathrm{L} \leq \mathrm{Z} \leq \mathrm{L}
\end{gathered}
$$

\subsubsection{Meshing the geometry}

Simulation was done using structured mesh. Tetrahedral meshing is used for the domain.

\subsection{Fluent (solver)}

After meshing and quality check of the mesh, the domain is imported into fluent software and various setting parameters are given.

Table II. Solver parameters used for simulations

\begin{tabular}{|l|l|}
\hline Parameter & Setting \\
\hline Solver & 3D Segregated, Unsteady, Implicit \\
\hline Velocity formulation & Absolute \\
\hline Viscous model & SST $k-\omega$ \\
\hline Pressure-velocity coupling & $\begin{array}{l}\text { PISO (Pressure Implicit with } \\
\text { Splitting of Operators) }\end{array}$ \\
\hline Pressure discretization & Body force weighted \\
\hline Momentum discretization & Quick \\
\hline Volume fraction & Modified HRIC \\
\hline Turbulent kinetic energy and energy dissipation rate discretization & Second order upwind scheme \\
\hline
\end{tabular}

\subsection{Results from CFD}

Pressure force on the sail

$$
\begin{aligned}
& =-197.689 \mathrm{~N} \\
& =-62.508 \mathrm{~N}
\end{aligned}
$$

Total drag resistance acting on the sail $=-260.198 \mathrm{~N}$ 


\section{Structural Analysis In Fem}

The drag force obtained from CFD. From drag force pressure is calculated and used in FEM .The sail shape is modeled in CATIA and imported into ABAQUS software. In this sail, mast and sail with mast is analysed and deflection and stresses are determined.

\subsection{Analysis of sail NACA0018}

\subsubsection{Modelling}

ABAQUS was used to carry out the finite element analysis in the work. The dimension of the specimen was 600 $\times 2000 \mathrm{~mm}$ in width and height. Aluminium is the material provided for sail. Young's modulus of sail is 69000 $\mathrm{N} / \mathrm{mm}^{2}$. Poisson's ratio is 0.3 .The C3D8R element is used in analysis. The element is a solid, linear brick element, with reduced integration. It is an 8 noded element.

\subsubsection{Loads}

$$
\begin{aligned}
\text { Pressure } & =\frac{\text { load }}{\text { area of sail }} \\
& =\frac{260.19}{(2000 \times 600)} \\
& =0.00022 \mathrm{~N} / \mathrm{mm}^{2} .
\end{aligned}
$$

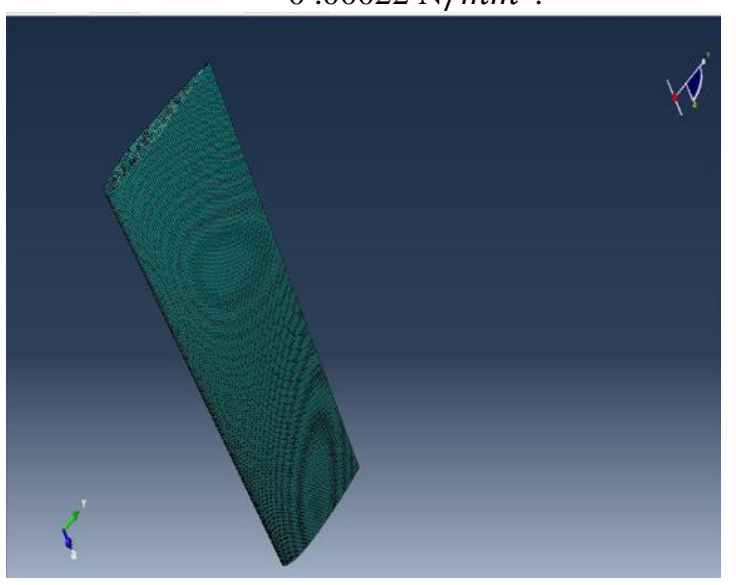

Fig 2: Mesh diagram of the model

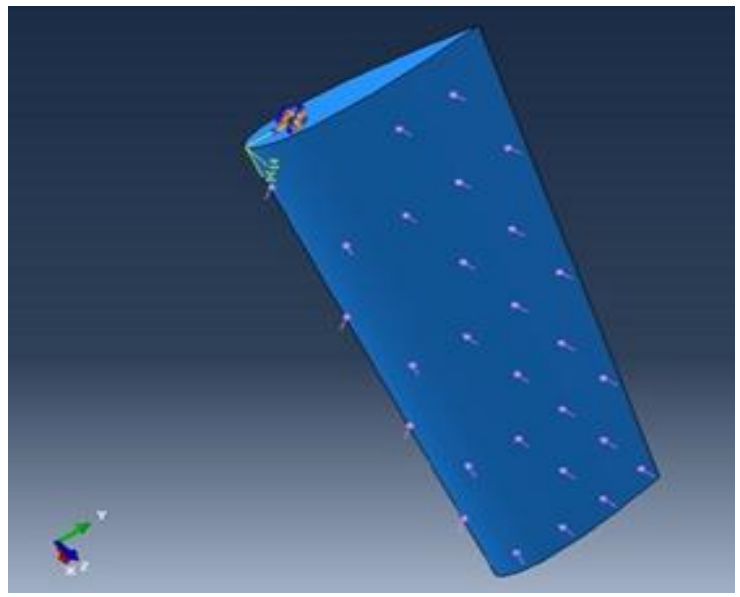

Fig 3: Loading diagram of model

\subsection{Analysis of mast}

\subsubsection{Modelling}

Diameter of the mast provided is $50 \mathrm{~mm}$. High tensile steel is the material provided for mast. Young's modulus of sail is $210000 \mathrm{~N} / \mathrm{mm}^{2}$. Poisson's ratio is 0.3.Pressure provided on the mast is $0.00022 \mathrm{~N} / \mathrm{mm}^{2}$.

\subsection{Analysis of sail with mast}

\subsubsection{Modelling}

The dimension of the specimen was $600 \times 2000 \mathrm{~mm}$ in width and height. The mast is provided with $50 \mathrm{~mm}$ diameter along the leading edge. Fixed boundary condition is provided on the mast. Pressure applied is 0.00022 $\mathrm{N} / \mathrm{mm}^{2}$.Materials properties of both sail and mast are given in table below

Table III Material Properties

\begin{tabular}{|l|l|l|}
\hline Material & Young's modulus & Poisson's ratio \\
\hline Aluminum & $69000 \mathrm{~N} / \mathrm{mm}^{2}$ & 0.3 \\
\hline High Tensile Steel & $210000 \mathrm{~N} / \mathrm{mm}^{2}$ & 0.3 \\
\hline
\end{tabular}



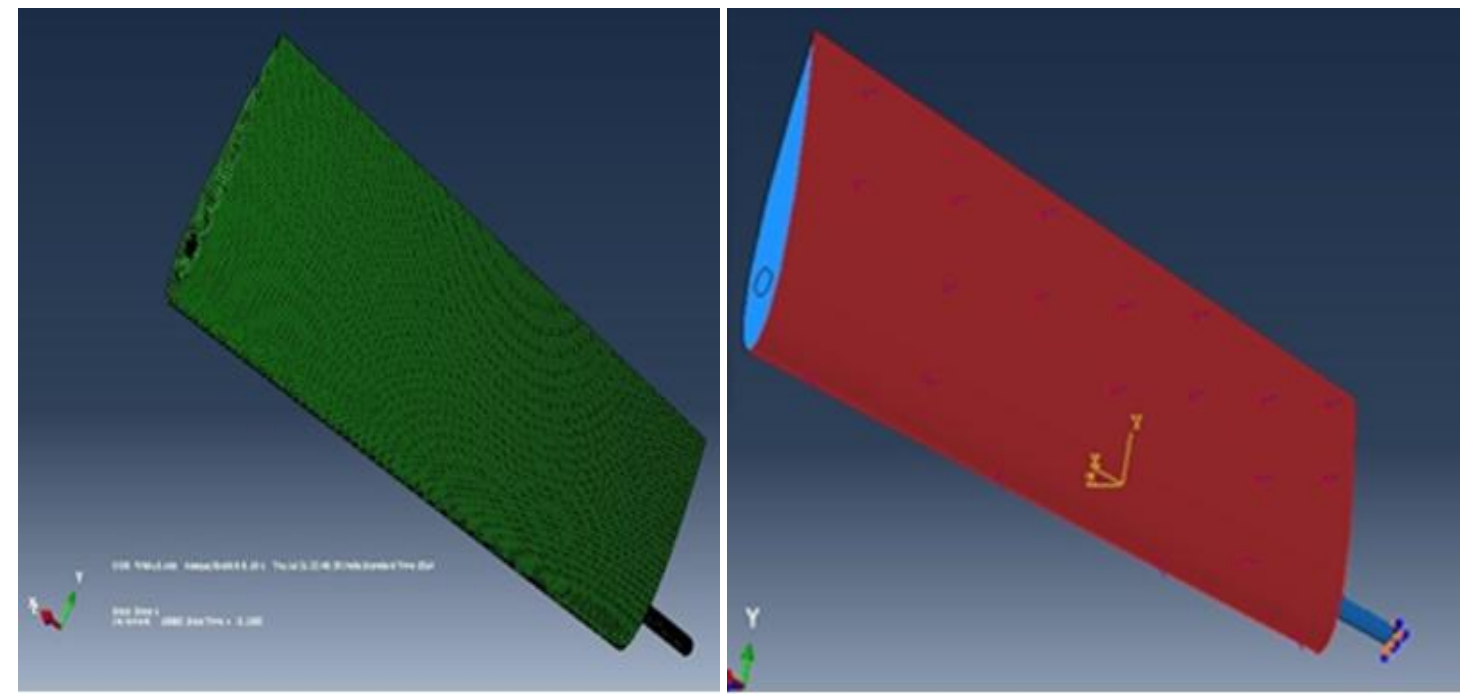

Fig 4: Meshed diagram of sail withmastFig 5:Loading diagram of sail with mast

\section{RESULTS AND DISCUSSIONS}

In this work NACA0018 airfoil is used for structural analysis and 50mm mast is used. Sail, mast, sail with mast are analysed and the results are obtained. Stressof mast and sail with mast are same. So 50mm diameter can be successfully used for sail NACA0018.

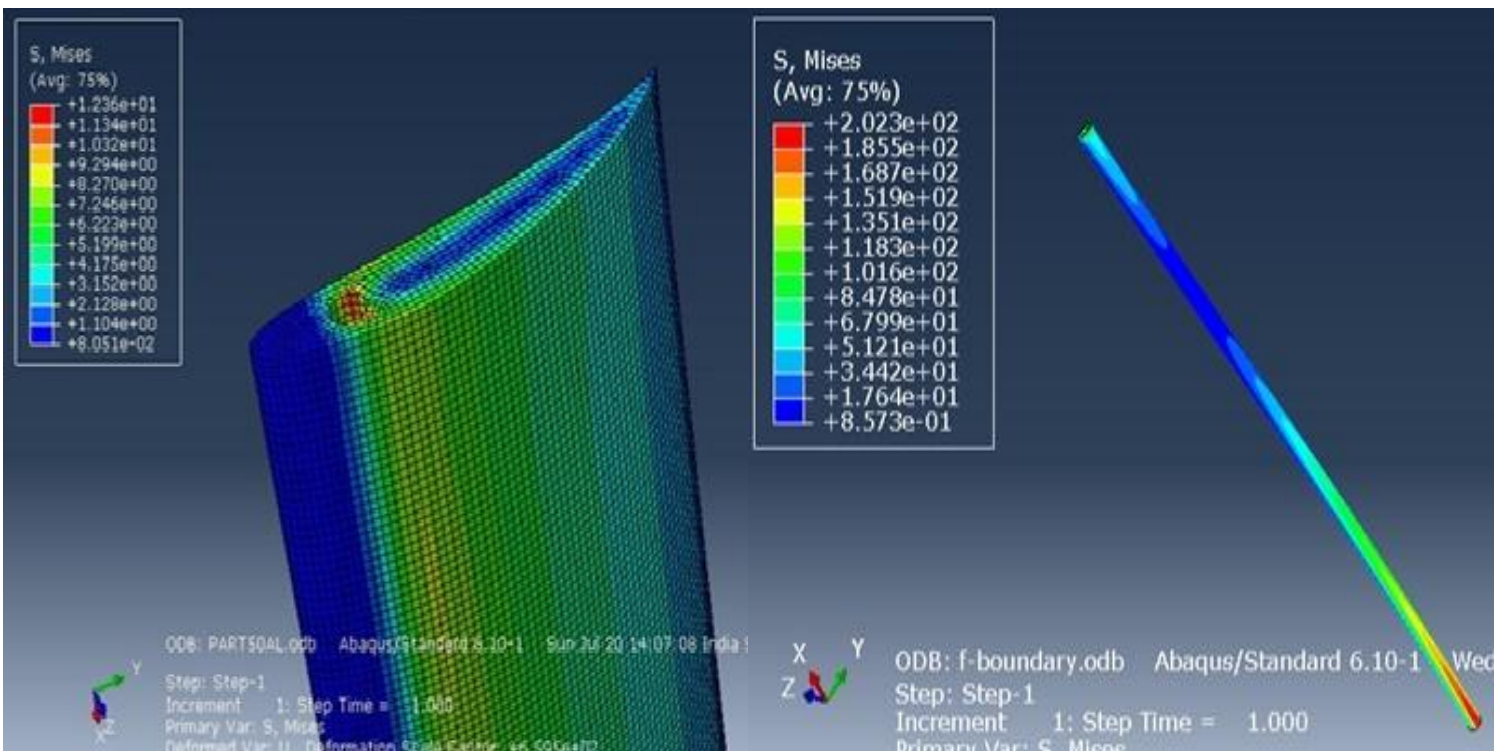

Fig 6: Stress diagram of sail modelFig 7: Stress diagram of mast 


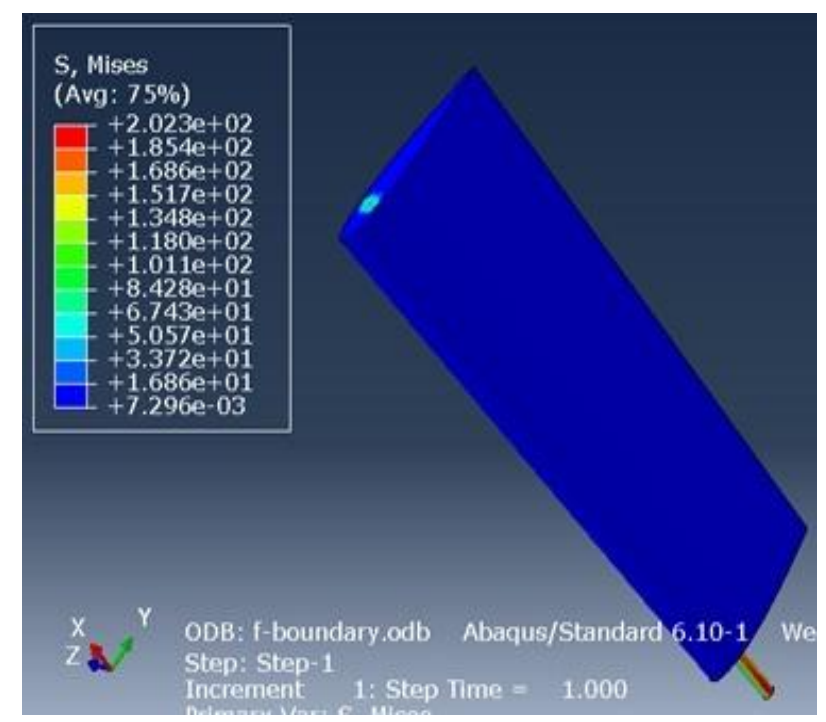

Fig 8: Stress diagram of sail with mast

TableIV Results of Structure

\begin{tabular}{|l|l|l|}
\hline Material & Deformation & Stress \\
\hline Sail & $3.033 \times 10^{-1} \mathrm{~mm}$ & $1.236 \times 10^{1} \mathrm{~N} / \mathrm{mm}^{2}$. \\
\hline Mast & $6.773 \times 10^{1} \mathrm{~mm}$ & $2.023 \times 10^{2} \mathrm{~N} / \mathrm{mm}^{2}$. \\
\hline Sail with mast & $6.780 \times 10^{1} \mathrm{~mm}$ & $2.023 \times 10^{2} \mathrm{~N} / \mathrm{mm}^{2}$. \\
\hline
\end{tabular}

\section{CONCLUSIONS}

CFD and structural analysis of the sail were carried out

- Standard sail NACA0018 is analysed, in which wind acts perpendicular to the sail.

- The maximum drag force value obtained is $260.19 \mathrm{~N}$.

- A finite element based methodology was successfully applied to determine deformation and stress of sail.

- Maximum value of stress is $2.023 \times 10^{2} \mathrm{~N} / \mathrm{mm}^{2}$.

- It can be concluded that mast of $50 \mathrm{~mm}$ diameter can be sucessfully used in NACA0018 airfoil.

\section{REFERENCES}

[1] Banks J, Webb A, Spenkuch T, Turnock S.R.(2010) Procedia Engineering 2 "Measurement of dynamic forces experienced by an asymmetric yacht during a gybe, for use within sail simulation software"pp 2511-2516 Southampton, SO171BJ, UK.

[2] Dr. Robert Ranzenbach, Dave Armitage, Adolfo Carrau "Mainsail Planform Optimization for IRC 52 Using Fluid Structure Interaction'"The 21st Chesapeake Sailing Yacht Symposium Annapolis, Maryland, March 2013.

[3] E. Dias and C. Silva (2000) "Analysis of flow conditions in a candle boat using computer dynamics offluids"International Conference on Computational Methods in Environmental and Thermal Engineering.

[4] Francisco Perez -Arribas, Patricia Izaguirre -Alza, Luis Perez -Rojas, Alberto Torres - Benayas (2012) Procedia - Social and Behavioral Sciences 48 “EU- Cargo Xpress :Wind Propulsion Concept"pp 1314 - 1323, Victoria, 20844, Madrid.

[5] Ignazio Maria Viola, Raffaele Ponzini, Daniele Rocchi, Fabio Fossati “Analysis of Aerodynamic Indices for Racing Sailing Yachts: a Computational Study and Benchmark on upto 128 CPUs." The twentieth in the high-level international series of parallel computing in computational fluid dynamics, pp 61-69 May 2008.

[6] I M Viola, S Bartesaghi, T Van-Renterghem, R Ponzini (2013) “DelayedDetached Eddy Simulation of Sailing Yacht Sails"The Third InternationalConference on Innovation in High PerformanceSailing Yachts, Lorient, France,129-143 June 2013.

[7] J. Garcia-Espinosa and I. Ortigosa "A Calculation/Simulation System of Sails Communicated IN Real Time With Wireless Sensors"'International Conference on Computational Methods in Marine Engineering MARINE 2009.

[8] M. Riotte, M.E. Biancolini, I.M. Viola, (2014) "Sails trim optimisation using CFD and RBF mesh morphing". Journal of Computers and Fluids, volume 93, 46-60. 